\title{
Analysis on Long-term Investment in Stocks
}

\author{
Yicheng $\mathrm{Xu}^{1, *}$
}

\author{
${ }^{I}$ The Pennsylvania State University State College, PA 16801 \\ *Corresponding author. Email: yxu6166@gmail.com
}

\begin{abstract}
China has a large number of financial practitioners, the number of stock investors far exceeds the number of financial practitioners. This will shows that there are a large group of people who know nothing about finance in the current Chinese stock market. They may not have a lot of financial knowledge. Their decision to invest in the stock comes from hearing the news. When these people see the stock rising, they are excited to invest more money. When these people see the stock falling in a period of time, they think that their chosen company has lost hope and quickly look for another company. Meanwhile, these people dream of obtaining high returns through simple work and really short time. So what kind of investment method is more suitable for some people without any financial background? After the research, we find that people who choose to hold stocks for a long time and don't care about the short-term fluctuations of stocks are more likely to make profits in the stock market. As opposed to those who prefer to make quick profits by making short, frequent trades.
\end{abstract}

Keywords: Long-term, stable, value investment

\section{INTRODUCTION}

We all know there is no such investment that can make profit for you without any risk. Even if you put your money in the bank, the interest you earn does not even exceed inflation. At the same time, High profit returns are often accompanied by high risk. History is not deceitful. We look back in history and we find a lot of interesting facts about investing. If we compare investments that are stable over a long period of time with investments that are frequent over a short period of time by watching the current five years stock price of some companies fluctuate. In the absence of a specific form of short-term operations and in consideration of human fluctuations, Long-term investments generally yield a considerable return. The difference between long-term investment and short-term and frequent investment is that long-term investment ignores human weaknesses and investors' decisions are not guided by short-term fluctuations in stock prices. The long term investment horizon is over a longer period like three years, five years rather than one month or two months or even a week. So is it more profitable to trade stocks more frequently for a short period of time or more profitable to hold a stock for a long time? After comparing the long-term performance and short-term performance of different leading companies in different stock markets, we will finally come to a conclusion which of the two different investment styles will have more stable returns. In the future, there will be more people who are not finance majors trying to invest in stocks in order to beat inflation. I believe that this paper will help these people have a basic concept of future investment methods.

\section{ANALYSIS OF STOCK INVESTMENT}

\subsection{Short-term}

It is possible to succeed in a short term on a scientific and standardized training platform under the guidance of a professional teacher. However, for most individual investors, the short term is still difficult. Short-term and frequent operations are a challenge to human nature. People can't get rid of human weakness, But if you invest for the long term, that means you are careless about short-term fluctuations in stock prices. What you really get is a long-term return. If you look at the stock prices of most of the best companies in recent years, you will find that long-term investments have paid off more handily than short-term, frequent investments.

I believe the purpose of most people who buy the stock is to earn profit. As expected, every investor used to think using the least amount of time and cost to get the most benefit, but countless facts prove that most 
people failed in this mind or operation style in stock. It can't be denied that there are still some people who make considerable profit using very frequent trading in a really short time. Therefore, having a correct investment style is important for general inverters to make a considerable profit or avoid losing money as much as possible.

The long term is easier to succeed than the short term, one is the market, one is the trader's own reasons. From the market's point of view, the trend of the big cycle will go more firmly. The fundamentals of the big cycle generally do not turn suddenly, but can cause the fundamental change of the big cycle, usually there is a budding and mature process. In this process, gradually attract capital to promote. More capital is needed to push the trend of the big cycle or to change the original trend of the big cycle. Short term small period trend is more random, the smaller the more random. Because small cyclical trends contain small amounts of capital. An hour-long trend within a day can change the original trend with just one data point. Many main agencies can also do technical fake action in a small cycle, fake breakthrough.

Technical analysis, the larger the cycle is more effective, the smaller the cycle is more ineffective. For example, in forex, a daily pattern that takes more than three months will have a $90 \%$ chance of causing a trend once it breaks out, while an hourly pattern that takes more than three months will not have such a high probability of causing a trend once it breaks out. If you look at minutes, the pattern is even less effective.

From the traders themselves, trading is a very mental activity, we need to keep healthy, energetic, avoid tired trading, tired trading will cause confusion, gambling is easy to stimulate. Controlling risk is the only way to trade profits. risk comes from misreading the market and arousing emotions. In the long term, because of the long time interval, full rest, thinking more fully, this is more conducive to clear thinking, emotional control, so as to reduce the risk of trading. Short term, the trade is relatively frequent, frequent trade is extremely mental, when we are tired, people's emotions are not easy to control, random orders, gambling stimulation is easy to appear.

\subsection{Long-term investment in great companies}

Nowadays, by the end of June, 2021, the number of investors in the stock market had reached 189 million [1]. At the end of July last year, the number of stock market investors topped 170 million for the first time. In other words, in the past nearly a year, the number of investors in the stock market continued to maintain a steady growth trend. China also has more than 8 million financial workers of all kinds. Investing in stock means investing in a good company. Moutai are called by
Chinese stock legends. It has the highest market value in Chinese stock value. On August 27, 2001, Kweichow Moutai went public with an ipo price of 31.39 yuan per share. The opening price was 34.51 yuan and the closing price was 35.55 yuan on the first day. As of July 3, 2012, the stock price of Kweichow Moutai closed at 254.94 yuan, after the resumption of rights, the stock price is 1222.47 yuan (excluding cash dividend), up 38.94 times. On February 10, 2021, Moutai's share price even reached an all-time high of 2581.71 [2]. This year's peak for the stock price compared to twenty years ago Moutai, The stock price rose nearly 83 times. We can see that Moutai is really a good company, but legends don't last forever. On July 16, 2012, Kweichow Moutai hit an early high, with a re-entitlement price of 129.3 yuan/share, and then began to restrict the consumption of San Gong, plasticizers broke out, news events unfavorable to Moutai were overwhelming, and resistance fell again and again, 2013 On April 8, 2005, the lowest price of Kweichow Moutai was 44.89 yuan/share. Imagine if you unfortunately are an investor who has Moutai stock in 2013, Do you think you will still hold this stock with a $65 \%$ retracement of the share price? Can you imagine after ten years the stock price will hit 2000 yuan? Or Do you have enough confidence by doing the short operation during 2013 and still making profit from Moutai?

The stock market in different countries sometimes has the same phenomenon. Alibaba Group was founded in 1999 in Hangzhou, Zhejiang by 18 people led by Former English teacher Jack Ma. Alibaba Group operates a number of businesses include: Taobao, Tmall, AliExpress, Alibaba International Exchange, Aliyun, Ant Financial, etc. On September 19, 2014, Alibaba Group was officially listed on the New York Stock Exchange, creating the record of the largest IPO in history. If you bought Alibaba stock in June in 2018, You were buying at a stage high price in this period of time. In the next six months, if you still hold the Alibaba stock, you will face a $40 \%$ drop in the stock price. But If you make friends with time, after a year, the stock price will come back to the peak in 2018 June [3].

In fact, the two examples the author gave are in retrospect. In the case where we already knew the results, we can see if the company you choose doesn't have fundamental problems then short-term fluctuations in stock prices can't really determine the stock price in the long term. What the author said about the "fundamental problems" is a company still making a considerable profit, and maintaining steady or even higher profit growth rates. Stock is not a hard way for people who do not imagine to coin money overnight. It will give considerable profit to investors who are patient enough and they have to believe in the company they choose. Believing the company means you can withstand short-term fluctuations in the stock price of the company, and you won't sell the stock and forget 
your original research because of a short-term stock price pullback. A very funny event happened in China, An old woman went to the securities service to handles business, because be in abroad all the year round already forgot her stock account password, come to close door now, discover oneself spend 50 thousand yuan to buy the stock Changchun High \& New Tech Industry Inc unexpectedly in 2008, account market value already reached 5 million yuan now [4]. This seems to be an innocent operation, but from another perspective is a good interpretation of what is called long-term investment

\subsection{Long - term investment in industry head companies}

Over the past 200 years of American history, there has been a financial crisis of varying magnitude almost every dozen years. Founded in 1812, Citibank has been an old company for 197 years until 2009. Its life is almost the life of Wall Street. In every sense, Citibank is the symbol of Wall Street, as well as the symbol of American financial strength. Before the outbreak of the subprime crisis in 2007, Citi was the world's largest bank with a market value of $\$ 300$ billion and the world's largest bank with a profit level of more than \$27 billion a year [5]. But such is the cruelty of the world that when the housing bubble that had been nurtured before 2007 burst and unleashed a financial tsunami, old companies that had seemed undefeatable before may not be. In early 2009, Citigroup's market value fell to less than $\$ 2.5$ billion. Through October to November, 2008, the Treasury and other federal government agencies invest at nearly $\$ 50$ billion to citi, and to provide hundreds of billions of guarantee, is not enough, to early 2009 citigroup by sovereign wealth funds, institutional investors and the U.S. government raised more than $\$ 1000$ in capital, ultimately rely on the U.S. government's comprehensive aid to avoid bankruptcy, which makes the U.S. government citi's largest shareholder. Historical experience shows that the business development of companies follows a law: excellent companies are likely to continue to be excellent, while mediocre companies tend to continue to be mediocre, and most of the bad companies go to the destruction of value. Companies that gain a decisive advantage in business competition and become the leader in an industry tend to enjoy the fruits of longterm victory. A study of the American business market found that of the 25 leading brands from 1923 onwards, 20 retained their lead 60 years later, four are now at number two and one is at number five [6].

Judging by Citibank's crisis, investing in an industry leader is usually a good long-term investment. The stock can become bibcock is necessarily the strongest which stock, general stock rises the biggest, bibcock is to start first commonly, the stock of other same plate just follow the wind to rise just.When encounter adjustment falls when, bibcock is also drop the smallest that only, bibcock is carrying because of powerful capital, even if fall hind also can be repaired very quickly come back. In fact, investment is also a game of probability, we should choose a good company from the perspective of high probability to hold for a long time, rather than trying to dig a dark horse with low probability, because the odds of investment are not great. Doing investment, people want to pursue the relative certainty of performance to allocate excellent performance of the blue chip [7].

\section{CONCLUSION}

Consequently, looking back at history, a long-term investment is more easily and reliably profitable than frequent and short operations, but it's not mean you will hold your stock forever. So when is the right time to sell your shares? The answer is never. The only time you might think of selling your stock is when you need to use this money to do something really important for you or you find any other companies might have better potential to earn profits. The point is when you buy the stock, you should ask yourself "Do I need this money next year?" Or even ask yourself, "Do I need this money in the next three years?" If your answer is yes, you should not buy the stock.

In the long run, good companies should be able to see sustained growth in the future. There are several factors to consider in determining a good company and investing in its long-term value. First of all, the company should be in a rising industry, because the sunset industry may make it difficult for all companies in the industry to have sustainable growth opportunities. Second, earnings growth, with stability and certainty, rather than a year of gains and losses, like a cyclical stock with large fluctuations in earnings. At the same time, the company needs to have a moat, that is, a listed company should have core competitiveness. Only in this way can other competitors be prevented from entering the industry. In terms of financial return, the ROE should be more than $20 \%$, and the net asset liability ratio should be less than $30 \%$, which also refers to the stock selection index of Buffett [8].

The stock market is a good investment channel. The premise is you can put less emphasis on short-term fluctuations in stock prices, avoid being jealous when a stock goes up, or give up your initial faith in the company when it goes down. When you extend your investment period and calm your mind, I believe you can make a difference in the capital market. As long as the valuation is not too expensive to buy, buy some leading stock portfolio investment, the final result will not be too bad, long-term holding probability will exceed their expectations. 


\section{AUTHORS' CONTRIBUTIONS} $\mathrm{Xu}$.

This paper is independently completed by Yicheng

\section{ACKNOWLEDGMENTS}

I would like to express how much I like your class. Thanks for making the class content interesting and making us study in a relaxed environment. Through your course, I not only learn knowledge from the textbook, but also from your experience you shared in class. Professor Sun said in class that she did not sell her stocks in time during the 2008 American financial crisis. However, after suffering losses, her only action was to put her stocks without any operation. After a period of time, the prices of these stocks helped her make money. Her sharing of this experience also inspired me to write this paper. Professor Sun is not only a teacher for me, you are more likely a friend for me, I can share my funny experiences with you, and even some life problems you can help me to solve. Thank you, professor sun, for successfully making a positive impact on the class. You will always be missed.

\section{REFERENCES}

[1] KuaiKeji, The number of Chinese investors has reached 189 million for 31 consecutive trading days. Sep, 02, 2021.http://stock.hexun.com/202109-02/204290294.html

[2] Kweichow Moutai Co., Ltd. (600519.SS), Sep, 09, 2021. [Stock quote]. Retrieved from https://finance.yahoo.com/quote/600519.SS?p=600 519.SS

[3] Wikimedia Foundation. Alibaba group. Wikipedia. Aug, 29 , 2021. https://en.wikipedia.org/wiki/Alibaba_Group.

[4] 100 times in 13 years! Dalian a dama fire: 0850 thousand fry after forget the password, cancel the account found to change 5 million..., 21st Century Business Herald. Apr, 24, 2021. https://finance.sina.com.cn/stock/quanshang/qsyj/2 021-04-24/doc-ikmxzfmk8644279.shtml

[5] Zhiwu Chen, The 2008 financial crisis: Will history repeat itself. Dec, 06, 2020. https://finance.sina.com.cn/roll/2020-12-06/dociiznezxs5422499.shtml

[6] Nanshan Road, The simplest and most effective investment strategy is to buy the dragon head. Aug, 24 , 2019.
[7] Delong Yang, Value investing seeks certainty of long-term performance. May, 14, 2021. https://www.yicai.com/news/101050290.html

[8] Charles Rotblut, 14 Return-On-Equity Champions With Warren Buffett Fundamentals. May 29, 2020. https://www.forbes.com/sites/investor/2020/05/29/ 14-return-on-equity-champions-with-warrenbuffett-fundamentals/?sh=300593b85587

https://xueqiu.com/7755398453/130623504 